\title{
Marcas em si: vivenciando a dor do (auto) preconceito
}

\author{
Marks on oneself: experiencing the pain of (self) preconception \\ Marcas en sí misma: la vivencia del dolor del auto preconcepto
}

\section{lací Proença Palmeira', Ana Beatriz Azevedo Queiroz", Márcia de Assunção Ferreira"}

' Universidade do Estado do Pará, Centro de Ciências Biológicas e da Saúde, Departamento de Enfermagem Comunitária. Belém-PA, Brasil.

"Universidade Federal do Rio de Janeiro, Escola de Enfermagem Anna Nery, Programa de Pós-Graduação em Enfermagem. Rio de Janeiro-RJ, Brasil.

\section{Submissão: 13-06-2012 Aprovação: 01-12-2013}

\section{RESUMO}

Pesquisa qualitativa cujo objetivo foi compreender as representações sociais do corpo por mulheres com alterações provocadas pela hanseníase, para que os cuidados de enfermagem possam atender de forma mais abrangente às suas necessidades. O referencial foi o da teoria das representações sociais. Participaram quarenta e três mulheres de uma unidade de referência especializada em dermatologia sanitária. Realizaram-se entrevistas, cujos conteúdos foram processados pelo software ALCESTE, o qual gerou uma classe cujos vocábulos associaram-se ao preconceito ancorado na autopercepção negativa da hanseníase. O esquema explicativo das representações sociais mostrou uma forte marca da memória social da lepra, cuja construção simbólica ampara-se no medo da doença. Concluiu-se sobre a necessidade de se investir na desconstrução de crenças arcaicas sobre a lepra para que se tenham novos modos de agir frente à hanseníase.

Descritores: Hanseníase; Corpo Humano; Preconceito; Cuidado de Enfermagem.

\section{ABSTRACT}

Qualitative research whose objective was to understand the social representations of the body by women with alterations caused by leprosy, for nursing care can meet more broadly to your needs. The theoretical framework was the social representations. Fortythree women participated, all of them from a reference unit specialized in sanitary dermatology. Interviews were conducted, which contents were processed by the software ALCESTE, generating a class whose words were associated with preconception anchored in the negative perception of leprosy. The explanatory framework of social representations showed a strong brand of the social memory of leprosy, whose symbolic construction sustains itself on fear of the disease. It was concluded on the need to invest in the deconstruction of archaic beliefs about leprosy so that to have new ways of acting towards the disease.

Key words: Leprosy; Human Body; Prejudices; Nursing Care.

\section{RESUMEN}

Investigación cualitativa cuyo objetivo fue comprehender las representaciones sociales del cuerpo por mujeres con alteraciones provocadas por la lepra, para que la atención de enfermería pueda atender de manera más amplia a sus necesidades. El referencial fue el de la teoría de las representaciones sociales. Participaron cuarenta y tres mujeres de una unidad de referencia especializada en dermatología sanitaria. Se realizaron entrevistas, cuyos contenidos se han procesado por el software ALCESTE, lo cual generó una clase cuyos vocablos se asociaron al prejuicio anclado en la autopercepción negativa de la lepra. El esquema explicativo de las representaciones sociales mostró una fuerte marca de la memoria social de la lepra, cuya construcción simbólica se ampara en el miedo de la enfermedad. Se concluye sobre la necesidad de se desconstruir las creencias arcaicas sobre la lepra a fin de que se tengan nuevas maneras de actuar frente a esta enfermedad.

Palabras claves: Lepra; Cuerpo Humano; Prejuicio; Atención de Enfermería. 


\section{INTRODUÇÃO}

A hanseníase é uma doença endêmica nacional e um grave problema de saúde pública. O Brasil, em 2009, obteve o $2^{\circ}$ lugar do mundo em número absoluto, com 37.610 casos novos ${ }^{(1)}$, perdendo somente para a Índia. O Pará, que acompanha a tendência da doença, nesse mesmo ano, foi o quinto estado brasileiro com o maior coeficiente de detecção: $55,70 / 100.000$ habitantes $^{(1)}$, ficando atrás de Mato Grosso, Tocantins, Rondônia e Maranhão, respectivamente.

Este coeficiente mede a força de morbidade, magnitude e tendência da endemia; avalia a carga de morbidade e de magnitude da hanseníase numa determinada população em intervalo de tempo determinado, bem como a população exposta ao risco de adquirir a doença. Assim, taxas elevadas são associadas a baixos níveis de desenvolvimento socioeconômico e a condições insatisfatórias do sistema de saúde, no que concerne ao diagnóstico precoce, o tratamento padronizado e ao acompanhamento dos casos.

Sendo uma das principais causas de incapacidades físicas no Brasil, atinge os indivíduos em seus estágios de vida mais produtivos, impondo à sociedade brasileira um elevado ônus social e econômico. Apesar de ser uma doença bíblica muito conhecida, ainda é pouco compreendida, pois a simples menção de seu nome ou a possibilidade de estar acometida por ela ainda causa terror por remeter à memória social da lepra e ao estigma milenar que acompanha essa doença, lembrando o isolamento, a mutilação e a exclusão sofrida no passado.

A hanseníase está inserida entre as prioridades do Pacto pela $\mathrm{Vida}^{(2)}$. A assistência integral à pessoa com hanseníase requer a organização de equipes multidisciplinares da rede pública de serviços do Sistema Único de Saúde (SUS), da Atenção Básica à média e alta complexidade, de acordo com a necessidade de cada caso e com os princípios de equidade e integralidade.

Dentre as ações de controle da hanseníase, a vigilância de $\operatorname{contatos}^{(3)}$ é fundamental para a interrupção da cadeia de transmissão da doença, pois permite o diagnóstico precoce dos casos. Contudo, no Pará, no ano de 2009, somente $52,5 \%$ dos contatos registrados foram avaliados ${ }^{(1)}$, acarretando a detecção tardia de casos, muitas vezes diagnosticados com incapacidades já instaladas, levando ao surgimento de alterações corporais visíveis que podem se traduzir em representações negativas sobre si e discriminação social.

A hanseníase desencadeia vários problemas que aparecem antes mesmo de seu diagnóstico definitivo, os quais decorrem dos comprometimentos dermatológicos e das manifestações neurológicas que comprometem a capacidade laboral. Quando é revelado o nome da hanseníase, ocorre um impacto no convívio familiar e a intensidade deste impacto está intimamente ligada aos conhecimentos prévios sobre a doença ${ }^{(4)}$.

Nessa perspectiva, ser portador de hanseníase configura-se numa vivência desencadeante de grande vulnerabilidade psicológica não só por se tratar de uma doença potencialmente incapacitante, mas, também, porque sua trajetória terapêutica induz, muitas vezes, a alterações estigmatizantes na imagem corporal (reações hansênicas) que repercutem na autoestima e na identidade das pessoas por ela acometidas e que têm o corpo alterado pela hanseníase.

Considera-se que a marca mais profunda causada pelo diagnóstico de estar com a hanseníase ou ter alterações corporais causadas por esta, seja o medo da rejeição dos outros. Esta situação foi mais bem observada a partir do contato direto com mulheres com o corpo alterado pela hanseníase, o que instigou a autora a buscar informações advindas de sua linguagem verbal, mas também não verbal, pela observação de seus corpos, pois as marcas na pele podem ser facilmente detectáveis se o profissional estiver capacitado para tal. Além da atenção ao que está visivelmente objetivado no corpo e ao tratamento medicamentoso, há que se atentar para os problemas psicossociais, ou seja, suas subjetividades, suas angústias, seus anseios, o modo como percebem as alterações em seus corpos e o impacto do diagnóstico e tratamento da hanseníase em suas vidas.

Faz-se, então, necessária a implementação de ações que abranjam a especificidade do Programa de Controle da Hanseníase segundo os princípios fundamentais de universalidade, equidade e integralidade requeridos pelo SUS. Com base nisso, cabe ao enfermeiro executar ações educativas abrangentes, atentando para as reais necessidades das mulheres e de seus conviventes no que tange à hanseníase, relevando suas subjetividades para que possam ser traçadas estratégias de ações capazes de promover a saúde e prevenir as incapacidades físicas, por meio de orientações individuais efetivas sobre o modo de transmissibilidade, cura e possibilidade de surgirem reações hansênicas durante o tratamento, com ênfase à prática de autocuidado com o corpo alterado, de modo a prevenir o agravamento de tais alterações, bem como as incapacidades físicas.

Nesta pesquisa, objetivou-se compreender as representações sociais de mulheres com hanseníase sobre o corpo com alterações provocadas pela doença, para que os cuidados de enfermagem possam atender de forma mais abrangente às suas necessidades.

\section{MÉTODO}

Pesquisa qualitativa, usando a Teoria das Representações Sociais (TRS), em sua vertente processual(5), como teoria e método. As representações têm por função uma produção de comportamentos e de relações com o meio ambiente, de uma ação que modifica aqueles e estas, e não de uma reprodução desses comportamentos ou dessas relações ${ }^{(5)}$. O campo de estudo foi uma Unidade de Referência Especializada (URE) em Dermatologia Sanitária situada no município de Marituba/Pará-Brasil, lócus de uma ex-colônia de hansenianos (Colônia de Marituba).

Participaram da pesquisa 43 mulheres com alterações corporais causadas pela hanseníase, estando em tratamento ou de alta por cura. Os critérios de inclusão foram: 1) idade adulta legal, faixa etária de 18 a 59 anos; 2) residir no município de Marituba-PA ou em Ananindeua-PA; 3) ser matriculada na URE; 4) fazer qualquer tipo de tratamento na URE mesmo que estivesse de alta curada; 5) aceitar participar do estudo. Foram considerados critérios de exclusão: qualquer alteração corporal que não fosse causada pela hanseníase, estar gestante e/ou puérpera e ser ex-moradora da Colônia de Marituba. 
A pesquisa de campo deu-se no período de julho a dezembro de 2009. Para a produção das informações foram utilizados dois instrumentos: um de caracterização do perfil sociodemográfico e clínico-terapêutico das mulheres e um roteiro de entrevista semiestruturado.

O Comitê de Ética da Escola de Enfermagem Anna Nery e Hospital Escola São Francisco de Assis, da Universidade Federal do Rio de Janeiro aprovou a pesquisa, sob protocolo $\mathrm{n}^{\circ}$ 31/2009. As mulheres assinaram o Termo de Consentimento Livre e Esclarecido, sendo-Ihes garantidos os direitos que cabem aos seres humanos que participam de pesquisas. Solicitou-lhes permissão para registrar seus discursos por meio de aparelho eletrônico (Gravador de voz). As expressões corporais foram captadas e anotadas em um caderno durante as entrevistas.

Ao final de cada entrevista, agradecia-se a participação e, se houvesse necessidade, procedia-se ao que se chamou "cuidado de enfermagem pós-entrevista". Destaca-se a aproximação desse cuidado com alguns pressupostos da convergência da pesquisa com a assistência, uma vez que durante a produção dos dados da pesquisa, se identificou que as mulheres precisavam ampliar informações sobre a cura, o contágio, a alimentação, a associação da hanseníase com a lepra, dentre outras.

Diante do exposto, houve necessidade de ampliar a interação entre a pesquisadora e as mulheres por meio de um trabaIho educativo individual com vistas ao diálogo sobre a doença, seu tratamento e cuidados relacionados ao corpo, à terapêutica medicamentosa entre outros. O objetivo foi o de elucidar suas dúvidas, introduzindo novos conhecimentos, desconstruir dogmas e mitos existentes sobre a hanseníase. Este foi um momento de convergência entre a pesquisa e a assistência, configurando-se em cuidado de enfermagem, com compartilhamento de saberes visando provocar mudanças no cenário da pesquisa ${ }^{(6)}$.

Posteriormente, todo o conteúdo das entrevistas foi submetido à análise lexical de conteúdo utilizando-se o Programa ALCESTE - Analyse Lexicale par Contexte d' um Ensemble de Segments de Texte. O pressuposto deste software é que pontos diferentes de referência produzem diferentes maneiras de falar, ou seja, o uso de um vocabulário específico é entendido como uma fonte para captar modos distintos de pensar sobre um mesmo tópico de interesse ${ }^{(7)}$.

O ALCESTE gerou um corpus formado por quarenta e três (43) u.c.i. (unidade de contexto inicial). A partir de então, o software repartiu o corpus em 858 u.c.e. (unidade de contexto elementar), formadas por 3.453 palavras ou formas de vocábulos distintos. Posteriormente, o programa reduziu os vocábulos às suas raízes, originando 619 palavras analisáveis. Dessa forma, de um total de 858 u.c.e., o programa selecionou 710 delas, perfazendo $83 \%$ do corpus.

\section{RESULTADOS E DISCUSSÃO}

O perfil sociodemográfico e clínico-terapêutico das muIheres do estudo

A faixa etária majoritária $(37,21 \%)$ das mulheres deste estudo foi de 29 a 38 anos; mais da metade (53,81\%) residia em Marituba; 53,50\% eram católicas; 34,89\% não completaram o ensino fundamental; 58,14\% tinham renda mensal que variava de 1 a 2 salários mínimos, e 58,14\% se ocupavam exclusivamente com os afazeres domésticos.

O perfil clínico terapêutico das mulheres apontou um grupo de mulheres majoritariamente multibacilar $(79,07 \%)$; com grau zero de incapacidade física $(53,49 \%)$; com episódios reacionais $(62,79 \%)$; e de alta curada $(69,77 \%)$, porém permaneciam vinculadas à URE para outros tratamentos.

\section{Análise e interpretação dos resultados após processamen- to do corpus pelo ALCESTE}

O ALCESTE definiu os grandes eixos de organização dos temas em quatro classes e seus léxicos com base em sua ocorrência e co-ocorrência. Porém, o sentido para tais classes e a identificação das representações sociais só pôde ser feita através da interpretação empreendida pela pesquisadora amparada na TRS.

Assim, à luz das classes formadas pelo Programa Alceste, com base no conteúdo discursivo e nos léxicos mais frequentes e mais característicos extraídos das u.c.e. de cada classe, procedeu-se as interpretações que geraram as nominações descritas no Quadro 1.

\section{Quadro 1 - Classes produzidas pelo ALCESTE com respectivas nominações.}

\begin{tabular}{|c|l|c|}
\hline Classe & \multicolumn{1}{|c|}{ Nominação } & No de u.c.e. / \% \\
\hline Classe 1 & $\begin{array}{l}\text { Cuidando do corpo que eu sou } \\
\text { para voltar ao corpo que eu fui: o } \\
\text { cuidado de si. }\end{array}$ & 153 u.c.e./ $21 \%$ \\
\hline Classe 2 & $\begin{array}{l}\text { A prática do cuidado prescrito e o } \\
\text { cuidado de si na reabilitação }\end{array}$ & 103 u.c.e. / 14\% \\
\hline Classe 3 & $\begin{array}{l}\text { Marcas em si: vivenciando a dor do } \\
\text { (auto)preconceito }\end{array}$ & 343 u.c.e. / 49\% \\
\hline Classe 4 & $\begin{array}{l}\text { Marcas causadas pelos outros: } \\
\text { vivenciando o medo do contágio }\end{array}$ & 111 u.ce. / 16\% \\
\hline
\end{tabular}

As classes 1 e 2 centraram-se nos sentidos do cuidado de si; e as classes 3 e 4 centraram-se no preconceito com relação ao tratamento e ao contágio.

Cabe esclarecer que, para fins desse artigo, serão explorados e discutidos os conteúdos presentes na classe 3 - Marcas em si: vivenciando a dor do (auto)preconceito. Trata-se de uma classe formada por 343 u.c.e. e 113 palavras analisáveis; sendo, portanto, a classe de maior significância estatística em termos de agregação de u.c.e., perfazendo 49,0\% do total.

Quadro 2 - Palavras representativas da classe 3 com respectivos $\chi^{2}$

\begin{tabular}{|c|c|c|c|c|c|}
\hline Palavra & $\chi^{2}$ & Palavra & $\chi^{2}$ & Palavra & $\chi^{2}$ \\
\hline tratamento & 36 & conversei & 12 & esconder & 09 \\
\hline hanseníase & 19 & triste & 10 & isolei & 08 \\
\hline cura & 18 & acabar & 09 & difícil & 08 \\
\hline gente & 16 & contei & 09 & Deus & 07 \\
\hline tempo & 16 & início & 09 & cabeça & 07 \\
\hline doença & 15 & pessoas & 09 & vergonha & 07 \\
\hline perguntam & 14 & superar & 09 & & \\
\hline
\end{tabular}


Para melhor ilustrar a discussão, apresenta-se um quadro com as palavras mais representativas da classe e respectivos qui-quadrados $\left(\chi^{2}\right)$, os quais sinalizam a importância semântica de cada palavra dentro desta a partir dos léxicos com $\chi^{2} \geq$ 7, conforme o Quadro 2.

Os vocábulos ilustrativos desta classe, associados às ideias centrais de suas u.c.e., apontam o preconceito ancorado na autopercepção negativa da doença, que tomam toma vulto a partir do diagnóstico e tratamento. As representações da doença objetivadas no preconceito foram evidenciadas através das seguintes palavras: triste, perguntam, esconder, isolei, vergonha. Tais palavras ganham mais sentido quando articuladas nos segmentos dos textos (u.c.e), as quais objetivam sentimentos diversos, tais como: não aceitação, omissão da doença, auto-isolamento, histórias de mutilações, dentre outros. Esta classe revela a ambivalência hanseníase/lepra, lepra/mutilação, mutilação/estigma, estigma/preconceito, preconceito/ exclusão social. O segmento de texto do discurso da mulher contido na u.c.e. a seguir, exemplifica esta interpretação:

Aí foi quando o chão se abriu, eu me vi toda mutilada. (u.c.i. 5 / u.c.e. $118 \chi^{2}=9$ ).

Esta descrição é compreensível ao pensar-se no estigma milenar que acompanha a doença, lembrando o isolamento e a exclusão sofrida no passado. Então, adoecer de hanseníase pode trazer à memória ideias antigas e preconceituosas, crenças que povoam o imaginário do senso comum ${ }^{(8)}$ e que, como tal, relacionam-se a questões sociais, culturais, biológicas e emocionais.

Vivenciar uma doença é relacionar-se de modo conflitante com o social, pois o doente passará a se sentir doente, quando deixar de realizar ações que lhe possibilitam pertencer ao contexto em que vive ${ }^{(9)}$. Dessa forma, o momento da descoberta da hanseníase pode desencadear sentimentos diversos, de tristeza, revolta e não aceitação, pois o significado da doença depende do sentido que lhe é atribuído, e isso se vincula a fatores imbricados nos grupos, tais como as experiências passadas, os preconceitos culturais e as informações obtidas pelos meios de comunicação.

Nos grupos é que se partilham os diferentes aspectos do cotidiano e edifica-se uma realidade comum através das representações sociais, que por isso são sociais e tão necessárias em nossa vida, uma vez que servem para guiar, nomear e definir os diferentes aspectos da realidade, no modo de interpretá-los, tomar decisões e, posicionar-se frente a eles de forma defensiva $^{(10)}$.

No início, eu ficava triste, chorava e não aceitava. (u.c.i. 37 / u.c.e. $791 \chi^{2}=14$ ).

As representações sociais da hanseníase ainda atrelam-se às mutilações e ao estigma ${ }^{(11)}$. Se tais representações sociais não estivessem atreladas ao preconceito, as mulheres deste estudo não o teriam. Mesmo vivenciando o processo da doença e o discurso das ciências nas unidades de saúde, ainda assim elas compartilham do preconceito que a sociedade carrega, sendo influenciadas e influenciando o meio e os grupos de seus pertencimentos sociais.

Assim sendo, acabam incorporando e dando um novo sentido a essa crença, que passa a fazer parte de seus cotidianos e dos seus discursos, ou seja, passam a reproduzir um saber compartilhado, mas com elementos que diferem de outros membros da sociedade, acrescentados, justamente, pela vivência da doença. Nas suas práticas cotidianas, elas vivenciam o preconceito que se materializa nas reações das pessoas com as quais convivem nos espaços sociofamiliares, o que vem a gerar comportamentos significantes, tanto dos outros com elas como delas com os outros.

A mamãe conversou com eles, mas, mesmo assim, eles ainda ficaram esquisitos comigo. (u.c.i. 30 / u.c.e. $640 \chi^{2}=18$ ).

Os comportamentos significantes que denotam exclusão potencializam os sentimentos negativos como a tristeza e a não aceitação da doença, deixando evidente o sofrimento das mulheres acometidas pela hanseníase.

É triste, não é bom para ninguém. [...] Foi a maior luta para eu me aceitar. (u.c.i. 4 / u.c.e. $92 \chi^{2}=7$ ).

Por outro lado, existem mulheres que frente a esses comportamentos significantes da sociedade, demonstram força na vivência da doença. A superação é demonstrada pelas mulheres como um processo intelectual e afetivo para tornar possível a mudança de conduta sobre o tratamento da hanseníase.

Tem que superar. Tem que ter força de vontade para superar. (u.c.i. 30 / u.c.e. $640 \chi^{2}=18$ ).

Outras mulheres pensam na cura, dando indícios que, de certa forma, se libertaram da representação socialmente construída de que a hanseníase não tem cura e faz cair partes do corpo. A possibilidade de ficar curada implica em mudanças de comportamento motivadas por querer-fazer e poder-fazer, que significa ficar melhor, diminuir as alterações, o estigma e o preconceito. Assim, pode-se dizer que, para essa mulher, o discurso técnico-científico se sobrepôs ao senso-comum.

Hanseniana eu não sou, eu não tenho mais a doença, eu já estou curada. Daqui para frente só quero ficar melhor. (u.c.i. 40/ u.c.e.819 $\chi^{2}=10$ ).

Para outra mulher, o cuidado prescrito por profissionais (autocuidado) foi uma forma de superar a doença, evidenciando assim a importância do enfermeiro e da equipe de saúde.

Eu me cuidei muito, tudo que as enfermeiras, o fisioterapeuta me diziam, eu fazia. Então eu tive forças para lutar. u.c.i. 21: 49-59a / Marituba / gi=1/ $r h=\operatorname{sim}$. (u.c.e. $n^{\circ} 450 \chi^{2}=10$ ).

Com a vivência da doença e a experiência adquirida com o tratamento, estas mulheres configuram-se como elementos-chave para a dinâmica das representações sociais, na medida 
em que, com acesso às informações do universo reificado, advindos de sua inserção no Programa Controle da Hanseníase, elas têm a oportunidade de acrescentar outros elementos aos saberes sociais construídos sobre esta enfermidade, contribuindo para a desconstrução de representações sociais cujos conteúdos fazem circular elementos que geram preconceitos sobre a hanseníase, reconstruindo-as.

Ao verbalizarem o processo de enfrentamento da doença e o percurso do tratamento, algumas explicações se amparam na crença na cura, na fé e na religião. As pessoas acreditam serem alimentadas por uma força superior que lhes ajuda a viver principalmente em momentos conflitantes, como na vivência de doenças graves. Nesse caso, a religião funciona como válvula de escape para onde poderão ser redirecionadas todas as suas angústias ${ }^{(12)}$.

Eu pedi muita força a Deus, só Ele mesmo para dar força para a gente. (u.c.i. 27 / u.c.e. $585 \chi^{2}=7$ ).

O fato é que a cura, a ausência de contágio e a ausência de sequelas orientam a prevenção e, assim, a busca imediata pelo tratamento emerge das representações como veiculo capaz de restabelecer a saúde, eliminar a doença, diminuindo as possibilidades de sequelas e, assim, tornar pública a doença, expondo-as ao preconceito dos outros. Nesse caso, o preconceito veiculado pelas representações sociais do corpo por mulheres com alterações provocadas pela hanseníase mostra um aspecto positivo ao servir de estimulo para o que não se quer - ser sua vítima - levando as mulheres a se prevenirem e buscarem o tratamento precoce, antes que a doença se objetive em marcas no corpo.

A demora em chegar ao diagnóstico representa uma falha nos serviços de saúde, que pode decorrer da falta de capacitação dos profissionais em diagnosticar e tratar precocemente a hanseníase ${ }^{(13-14)}$. Assim, o atraso no diagnóstico e tratamento subsidia a evolução da doença e o agravamento das alterações corporais.

Era diferente, mas era hanseníase. Quer dizer, eu perdi muito tempo para iniciar o tratamento, se tivesse começado logo que procurei talvez eu não estivesse assim. (u.c.i. 26/ u.c.e. $577 \chi^{2}=18$ ).

O contexto discursivo da u.c.i. supracitada evidencia a frustração da mulher com o sistema de saúde local, pois houve demora no seu diagnóstico (Era diferente, mas era hanseníase) e, consequentemente, retardo no processo de tratamento. Essa decepção fica mais evidente ao associar-se a fala à linguagem corporal captada pela observação da pesquisadora durante a entrevista: o discurso desta mulher foi entremeado por pausas, titubeios, lágrimas que chegaram ao pranto, e gestos, capazes de expressar tristeza, nervosismo e insatisfação, como: a mão cerrada batendo na outra espalmada, como se estivesse socando algo, e a mordida no lábio inferior cada vez que se referiria ao assunto.

A clofazimina, droga usada nos esquemas de tratamentos multibacilares da hanseníase, causa escurecimento na pele, dando-lhe uma tonalidade que varia do vermelho ao marrom escuro. Tais alterações, mesmo que reversíveis, podem perdurar por meses ou até mesmo, por anos para desaparecerem após o término do tratamento, se tornando um problema para as mulheres, pois, assim como as reações hansênicas, este medicamento provoca mais alterações na pele do que as já existentes. Dessa forma, o tratamento, que também visa matar o bacilo e evitar o contágio, além de minimizar as alterações presentes, acaba por agravar ainda mais a aparência.

Tu ficas pensando que a tua pele está escura e todo mundo vai saber e se afastar de ti. Esse tipo de preconceito que não sei se vou saber lidar, tipo aquele olhar que é capaz de te excluir sem precisar dizer nenhuma palavra. (u.c.i. 10 / u.c.e. $216 \chi^{2}=7$ ).

Na verdade, é necessário considerar as alterações da imagem corporal com que se confrontam estas mulheres, na medida em que são alterações visíveis e marcantes em seus corpos. Desta forma, mesmo considerando os benefícios do tratamento, os custos estéticos causados pela iatrogenia dessa terapêutica são muito difíceis de suportar, pois a alteração da coloração da pele objetiva a doença e a torna pública, desencadeando o medo da rejeição, levando-se em consideração o estigma e preconceito associados à doença. Assim, nos fragmentos de texto contidos na u.c.e $n^{\circ} 216$, essa mulher, ao saber que está com hanseníase, antecipa, em pensamentos, a estigmatização e o preconceito que a aguardam, tendo em vista já ter pertencido ao grupo dos potenciais estigmatizadores, ou seja, daqueles que não eram portadores de hanseníase e estigmatizavam os que tinham alterações corporais visíveis ${ }^{(15)}$.

A análise do corpus de dados em busca das representações das mulheres sobre o seu corpo alterado pela hanseníase possibilitou identificar expressões que denotavam objetivações e ancoragens ${ }^{(16)}$ nos esforços impetrados pelas mulheres em ressignificar seus corpos. Chama atenção o fato de tais expressões aparecerem quase sempre ligadas ao preconceito, reforçando a ideia de ser este o eixo central da classe.

Porque é uma doença que mutila e deforma as pessoas que não fazem o tratamento correto. Aí vira um bicho de sete cabeças, um bicho horrível. [...] Quando é na gente, vê que o bicho é feio mesmo. (u.c.i. 21 / u.c.e. $442 \chi^{2}=9$ ).

Então é uma cobra, eu tenho horror de cobra. Eu peço muita força para Deus. Tenho que aceitar meu corpo assim mesmo, porque a gente não quer, mas acontece. (u.c.i. 21 / Marituba / u.c.e. $445 \chi^{2}=8$ ).

As imagens acionadas para dar sentido à invasão da hanseníase no corpo é a de bichos, mais precisamente de um bicho de sete cabeças, que é uma metáfora que traduz muito bem a dimensão dessa invasão, ou seja, a dimensão da dificuldade de lutar contra e vencer a batalha. Um bicho de sete cabeças é uma expressão popular para falar de algo muito grande, uma enorme ameaça ou dificuldade que requer muita coragem para ser superada. Trata-se de uma expressão oriunda da 
mitologia grega, mas precisamente na lenda da Hidra de Lerna, uma monstruosa serpente com sete cabeças que, quando cortadas, regeneravam-se. Então, matar esse animal era uma tarefa muito difícil, o que explica as representações das muIheres veicularem reiterativamente a necessidade de ter muita força na luta contra a hanseníase.

Observa-se que no conteúdo semântico da u.c.e. 442, a ênfase é dada à necessidade da adesão ao tratamento, o que significa dizer que mesmo na vigência das reações hansênicas e do escurecimento da pele causado pela clofazimina, o tratamento seria a arma para se matar o bacilo e impedir que ele continue causando alterações no corpo. Do contrário, a doença ("o bicho") invade e transforma o corpo sem que nada possa ser feito.

A cobra denota de forma mais palpável o temor à doença, pois se trata de um animal peçonhento que também causa medo e repulsa, traduzindo objetivamente o sentimento que as mulheres desenvolvem de si, na autopercepção que têm de seu corpo em relação à observação da reação dos outros para consigo.

Na valoração das mulheres sobre a sua gravidade, a hanseníase foi aproximada ao câncer ou a Aids, na tentativa de entender o que, para elas, se apresentava como novidade. A novidade aqui se refere a como tais mulheres vivenciam as alterações que vão transformando seus corpos e que sentidos atribuem a esse processo. É esse processo de transformação corporal que elas ancoram no câncer e na Aids, as quais são doenças que também transformam o corpo e comprometem a aparência pessoal, tais como: as alterações na cor da pele, a lipodistrofia, dentre outras.

Eu acho que é uma das piores doenças. Eu acho que ela só não é pior do que o câncer e a Aids, mas ela acaba com a vida da pessoa do mesmo jeito.(u.c.i. 16/ u.c.e.354 $\chi^{2}=10$ ).

O recorte textual do discurso da u.c.i. 16, ao apontar a expressão "ela acaba com a vida da pessoa do mesmo jeito", remete à morte social, ou seja, a hanseníase não mata concretamente, mas discrimina, isola e leva a um processo simbólico de morte, no qual o corpo não perde sua materialidade. $\mathrm{O}$ exposto remete à idade média, aos rituais da igreja quando se isolavam os leprosos ${ }^{(17)}$. Outro exemplo:

Tem gente que quando sabe que está com hanseníase, se entrega, fica largado e morre.(u.c.i. 21 / u.c.e. $450 \chi^{2}=12$ ).

Esta maneira própria de sentir a doença, de perceber-se doente e de reorganizar a vida a partir da doença limita as possibilidades de viver e tratar a hanseníase, levando ao auto-isolamento e restringindo a participação social.

A relação de amizade dos portadores de hanseníase é permeada por um sentimento de receio recíproco e, por isso, utilizam-se de estratégias na tentativa de esconder a doença ${ }^{(13,18)}$.

Quando eu contei, ele me rejeitou [...] Ele não queria viver comigo, acho que tinha medo de pegar. Eu me sentia rejeitada por ele.(u.c.i. / Marituba (u.c.e. $141 \chi^{2}=8$ ).
Digo que é tratamento de nervo, porque se eu falar que é hanseníase, vai ficar todo mundo com medo de mim, como aconteceu com outra funcionária, que foi demitida devido a isso. (u.c.i. 36 / u.c.e. $768 \chi^{2}=10$ ).

Em síntese, as representações sociais do tratamento da hanseníase apontam o preconceito compartilhado socialmente sobre o estigma da hanseníase, que gera (auto)preconceito nas mulheres pela associação da hanseníase com a lepra, desencadeando sentimentos diversos por ocasião do diagnóstico e tratamento da hanseníase, apesar de ser este representativo de prevenção e cura, pois interrompe a transmissão da doença e preserva a integridade do corpo pela prevenção das incapacidades físicas, salvaguardando a identidade.

Figura 1 - Esquema explicativo das representações sociais do corpo (centradas no tratamento da hanseníase)

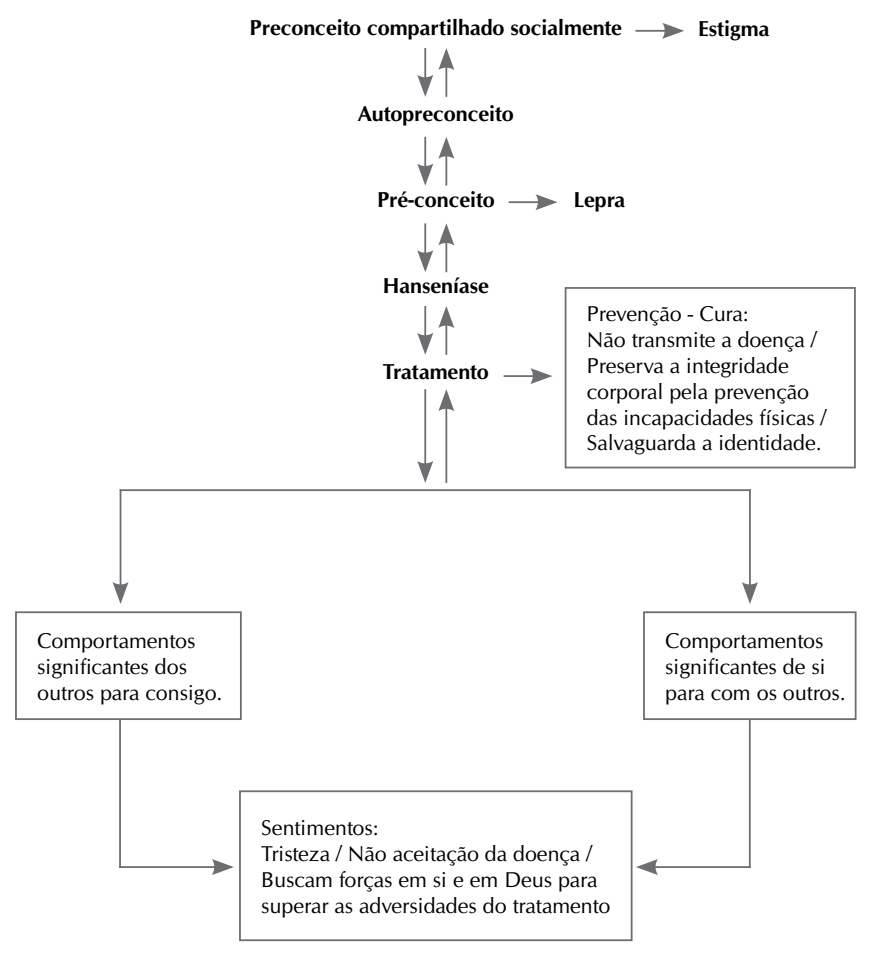

Quando tornado público, o diagnóstico e o tratamento da hanseníase geram comportamentos que, à luz da TRS, são denominados de significantes. Comportamentos esses dos outros para com as mulheres, tais como: demissão de emprego, rejeição do companheiro e de amigos, e de discriminação. O termo comportamento significante foi cunhado por Jodelet quando a autora identificou comportamentos sociais gerados em razão de representações sociais da loucura que vinham de encontro aos discursos que as mascaravam; ou seja, os comportamentos significantes revelam socialmente as representações de um grupo que nos discursos não são objetivamente manifestadas ${ }^{(19)}$.

As mulheres, por sua vez, aprendem a lidar socialmente com a doença e, também, passam a adotar comportamentos significantes para com os outros, tentando se proteger do preconceito. Assim, omitem ou mentem sobre o diagnóstico da 
hanseníase para não serem excluídas. Portanto, estas experiências as orientam a lidar com a doença na sociedade - orientando-as nas suas práticas e relacionamentos sociais. Esta síntese aponta elementos que, em articulação, conduz a organização de um esquema explicativo das representações sociais do tratamento da hanseníase, representado na Figura 1.

\section{CONSIDERAÇÕES FINAIS}

Os resultados oriundos desta pesquisa mostram que as representações sociais das mulheres sobre o seu corpo alterado pela hanseníase sofrem influência da memória social da lepra, ainda presente nas moradoras de Marituba e Ananindeua, atrelada à antiga Colônia de Marituba, cujas portas se fecharam em atendimento à política de saúde vigente.

Tais memórias ficam evidentes quando as mulheres falam sobre seus corpos que se transformaram, passando da beleza à feiura, sofreu morte social, isolamento e mutilações. O corpo alterado pela hanseníase objetiva-se em imagens metafóricas de animais repulsivos ou amedrontadores e ancora-se na história da lepra, do curso do câncer e da recente Aids, desencadeando nas pessoas atitudes preconceituosas de exclusão e humilhação que se repercutem nas mulheres em suas formas de se portarem socialmente e a lidarem com seus corpos e com as pessoas com as quais convivem, o que se evidencia em comportamentos de autoproteção no intuito de salvaguardarem suas identidades.

As representações sociais das mulheres sobre seus corpos se formam, basicamente, nos meios sociais onde vivem e convivem. Trata-se, portanto, de uma construção simbólica alicerçada por crenças, medo, terror, originando um grande tabu social que tem como pano de fundo a lepra.

A busca de estratégias para melhorar as ações de saúde dirigidas às mulheres e a seus conviventes apontam a importância da equipe de saúde e, mais precisamente, dos enfermeiros, para que, ao assisti-las, seja levada em consideração a subjetividade escondida por trás da objetividade demonstrada em seus corpos alterados, pois o modo como representam essas marcas pode suscitar um referencial de medidas educativas coerentes e voltadas as suas reais necessidades de saúde, ajudando o processo de reconstrução das representações sociais da hanseníase das mulheres e de seus conviventes, cujas ações estigmatizantes refletem o saber de seus pertencimentos sociais sobre o contágio.

Esta pesquisa desvelou que a atenção básica a ser prestada às pessoas acometidas por hanseníase deve transceder a relação profissional-usuário no âmbito do serviço, e ir além, abrangendo seus conviventes e a própria sociedade, em especial quando se tratar de uma enfermidade que marca o corpo e a história de vida de quem com ela convive, como é o caso da hanseníase.

Este estudo poderá contribuir para o campo teórico e prático no que tange ao cuidado de enfermagem às mulheres, uma vez que possibilitou emergirem experiências subjetivas de quem vive o processo da doença em seu corpo, revelando que a portadora de hanseníase não é acometida somente pelo bacilo, mas por uma avalanche de variáveis psicológicas como: medo, ansiedade, solidão e depressão, que repercutem negativamente na sua qualidade de vida, na evolução da doença, na instalação de incapacidades físicas, no cuidado de si e, também, no próprio sistema imunológico que parece ter uma leitura inteligível de tais problemas, manifestando-se na forma de reações hansênicas.

Nesse processo, a equipe de saúde, em especial o enfermeiro, pode ajudar na maneira de lidar com o impacto emocional da experiência, acompanhando e entendendo a subjetividade da mulher e seus conviventes, considerando-se os aspectos psicológicos e sociais que podem influenciar no processo da doença, seu tratamento e cuidado de si.

Com base nos resultados desta pesquisa, recomenda-se que os cursos de capacitação profissional devam não somente instrumentalizar os enfermeiros para o atendimento dos usuários acometidos com esta enfermidade focando nas repercussões anátomo-fisiopatológicas por ela causadas, mas especialmente atentar para os problemas advindos da subjetividade humana e das repercussões psicossociais que a vivência da hanseníase lhes traz, para que os cuidados de enfermagem sejam planejados de modo a atender de forma mais abrangente às suas necessidades.

\section{REFERÊNCIAS}

1. Ministério da Saúde [homepage na internet]. Secretaria de Vigilância em Saúde [acesso em 22 abr 2011]. Disponível em: http://www.hanseniase.datasus.gov.br.

2. Ministério da Saúde. Secretaria Executiva. Departamento de Apoio à Descentralização. Diretrizes operacionais: Pactos pela Vida, em Defesa do SUS e de Gestão. 2. ed. Brasília, DF: Ministério da Saúde; 2006.

3. Ministério da Saúde (Brasil). Portaria conjunta no. 125, de 26 de março de 2009. Define ações de controle da hanseníase. Diário Oficial da União 26 mar 2009;Seção 1.

4. Oliveira MHP, Gomes R, Oliveira CM. Hanseníase e sexualidade: convivendo com a diferença. Rev Latino-Am Enferm. 1999;7(1):85-91.
5. Moscovici S. A psicanálise, sua imagem e seu público. Petrópolis: Vozes; 2012.

6. Trindade WR, Ferreira MA. Grupo feminino de cuidado: estratégia de pesquisa-cuidado à mulher. Rev Bras Enferm. 2009;62(3):374-80.

7. Kronberger NE, Wagner W. Palavras-chave em contexto: análise estatística de textos. In: Bauer MW, Gaskell G, organizadores. Pesquisa qualitativa com texto, imagem e som: um manual prático. Petrópolis: Vozes; 2004. p. 416-441.

8. Luna IT, Beserra EP, Alves MDS, Pinheiro PNC. Adesão ao tratamento da Hanseníase: dificuldades inerentes aos portadores. Rev Bras Enferm. 2010;63(6):983-990. 
9. Adam P, Herzlich C. Sociologia da doença e da medicina. Bauru: EDUSC; 2001.

10. Jodelet D. As Representações sociais no campo das ciências humanas. Rio de Janeiro: EDUERJ; 2001.

11. Barbosa DM, Silva DMO, Rosa ETA. A percepção das perdas no âmbito psicossocial de indivíduos com deformidades na face em decorrência da hanseníase. Estudos 2007;34(1/2):101-118.

12. Silva PE. Aids e religiosidade: influências intersubjetivas aos acometidos pela epidemia. João Pessoa. Dissertação [Mestrado em Ciências Humanas]- Universidade Federal da Paraíba; 2009.

13. Eidt LM. Ser hanseniano: sentimentos e vivências. Hansen Int. 2004;29(1):21-27.
14. Baialardi KS. O estigma da hanseníase: relato de uma experiência em grupo com pessoas portadoras. Hansen Int. 2007;32(1):27-36.

15. Goffman E. Estigma: notas sobre a manipulação da identidade deteriorada. 4. ed. Rio de Janeiro: Guanabara Koogan; 1988.

16. Moscovici S. Representações sociais: investigações em psicologia social. 5. ed. Petrópolis: Vozes; 2007.

17. Rosen G. Uma história da saúde pública. São Paulo: ABRASCO; 1994.

18. Baialardi KS. O estigma da hanseníase: relato de uma experiência em grupo com pessoas portadoras. Hansen Int. 2007;32(1):27-36.

19. Jodelet D. Loucuras e representações sociais. Petrópolis: Vozes; 2005. 